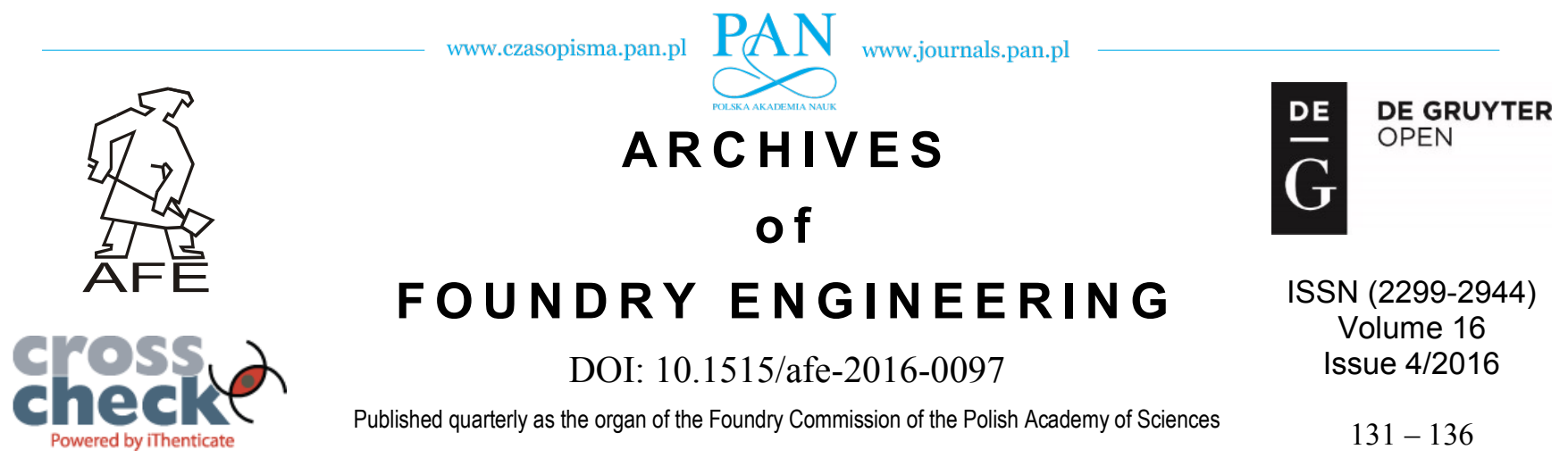

\title{
The Influence of Cyclic Sintering on the Structure and Mechanical Properties of Tungsten Heavy Alloy
}

\author{
P. Skoczylas, M. Kaczorowski * \\ Division of Mechanics and Armament Technology, Institute of Mechanics and Printing, \\ Faculty of Production Engineering, Warsaw University of Technology, Narbutta 85, 02-524 Warszawa, POLAND \\ *Corresponding author. E-mail address: m.kaczorowski@wip.pw.edu.pl
}

Received 13.04.2016; accepted in revised form 23.06.2016

\begin{abstract}
The results of structure and mechanical properties investigations of tungsten heavy alloy (THA) after cyclic sintering are presented. The material for study was prepared using liquid phase sintering of mixed and compacted powders in hydrogen atmosphere. The specimens in shape of rods were subjected to different number of sintering cycles according to the heating schemes given in the main part of the paper From the specimens the samples for mechanical testing and structure investigations were prepared. It follows from the results of the mechanical studies, that increasing of sintering cycles lead to decrease of tensile strength and elongation of THA with either small or no influence on yield strength. In opposite to that, the microstructure observations showed that the size of tungsten grain increases with number of sintering cycles. Moreover, scanning electron microscope (SEM) observations revealed distinctly more trans-granular cleavage mode of fracture in specimens subjected to large number of sintering cycles compared with that after one or two cycles only.
\end{abstract}

Keywords: Tungsten heavy alloy, Multiple sintering, Microstructure

\section{Introduction}

Weight heavy alloys (WHA) are the specific group of materials characterized with very high density and good mechanical properties. Their extremely high density is the main reason to use them for military applications. The examples are the penetrators for sub-caliber ammunitions [1, 2] often called Kinetic Energy Penetrators (KEP). Up to present the material commonly used is depleted uranium (DU). However, because of its radioactivity and more and more proofs concerning its harmful influence on human beings DU is continuously replaced with tungsten heavy alloys. When comparing these two materials it should be stated that DU is more convenient from a technological point of view because of much lower melting point which equals $1373 \mathrm{~K}\left(1100^{\circ} \mathrm{C}\right)$ only, compared to tungsten whose melting temperature is more than three times higher $3693 \mathrm{~K}\left(3420^{\circ} \mathrm{C}\right)$. Moreover, the depth of armour penetration of DU ammunition is approximately $10 \%$ higher than that with tungsten heavy alloy penetrator. This efficiency is ascribed to so-called "self-sharpening" effect, which is only occasionally observed in ammunition equipped with THA penetrators. Because of high melting point, tungsten heavy alloy are usually produced using powder metallurgy technique. The most widespread technique is liquid phase sintering (LPS) method where the mixture of elemental powders such as: tungsten, nickel, iron and sometimes cobalt is compacted and then sintered in hydrogen atmosphere furnace according to specific heating procedure. One of the main steps of manufacturing procedure is liquid phase sintering proceeded in a temperature range usually between $1763-1853 \mathrm{~K}\left(1490-1580^{\circ} \mathrm{C}\right)$. The material obtained has 
a specific microstructure consisting with hard tungsten grains embedded in relative soft matrix being the Ni-based solid solution. Because of this microstructure THA are often called tungsten composites. The results of our earlier studies [3, 4] showed that the mechanical properties and structure depend strongly on the parameters of LPS. Especially, there is high influence of temperature and time of liquid phase sintering on tungsten grain size and probably on tungsten grain- matrix interface.

During producing of THA in our Heavy Alloys Laboratory sometimes we have to repeat LPS procedure to correct the mechanical properties of THA. This is the reason why we decided to look closer into microstructure changes taking place during cyclic LPS process.

\section{Experimental procedure}

The tungsten alloy W96.2-Ni2.8Fe-0.8Co-0.2Mn was selected for the study. The powder components were mixed, compressed and then sintered in a hydrogen atmosphere according to the schedule given in fig.1. Details of heating procedure are given in table 1 . The specimens being studied were subjected to: $1,2,5$ and 15 sintering cycles. After a given number of sintering cycles the rod-shaped specimens were annealed for one hour at temperature $1173 \mathrm{~K}$ in vacuum furnace and then water quenched. After heat treatment the mini-samples for mechanical testing and structure observations were cut from the rod. Mechanical testing was carried out under tensile loading to evaluate tensile strength, yield strength and elongation of THA after 1, 2, 5 and 15 cycles of heat treatment.

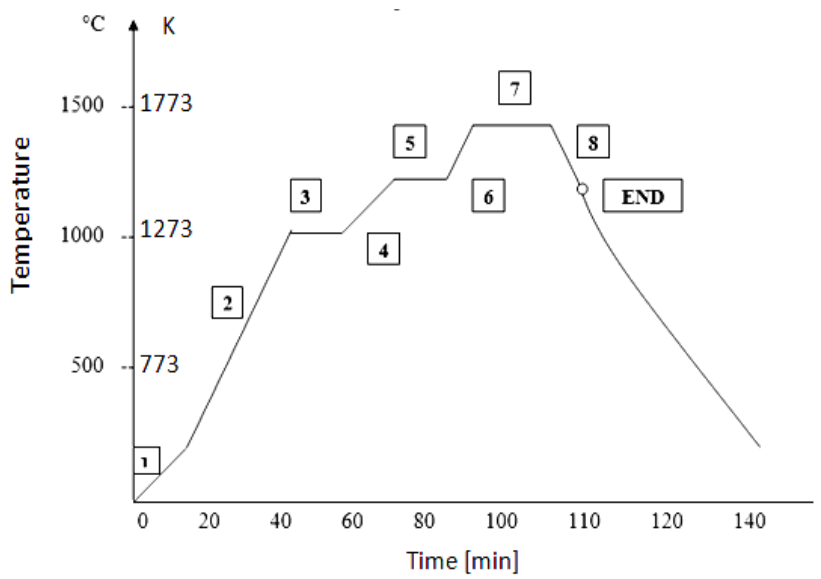

Fig. 1. Scheme of single heat treatment: (stage 7) - 20 minutes liquid phase sintering at temperature $1793 \mathrm{~K}$

Structure investigations included conventional metallography and scanning electron microscopy (SEM) studies. The specimen for metallography observations were first ground and then polished using Saphir 520 equipment. The microstructure was observed in Olympus IX-70 light microscope at different magnification. The typical microstructure photos were digitalized for quantitative analysis. For the qualitative analysis both longitudinal and transverse cross sections of the specimen were used. The analysis was performed using computer program and selected micrographs. SEM was used for fractography observations which were carried out on specimens fracture surfaces after tensile experiment. The fracture surfaces were studied at different magnification to reveal details of fracture mode.

Table. 1.

Description of heating procedure

\begin{tabular}{ccccc}
\hline $\begin{array}{c}\text { Segment } \\
\text { number }\end{array}$ & Segment & $\begin{array}{c}\text { Final } \\
\text { temperature }\end{array}$ & Time & $\begin{array}{c}\text { Heating/cooling } \\
\text { rate }\end{array}$ \\
\hline & & {$[\mathrm{K}]$} & {$[\mathrm{min}]$} & {$[\mathrm{K} / \mathrm{min}]$} \\
\hline 1. & Ramp & 373 & 5 & 20 \\
\hline 2. & Ramp & 1423 & 40 & 27 \\
\hline 3 & Soak & 1423 & 20 & - \\
\hline 4 & Ramp & 1753 & 20 & 15 \\
\hline 5 & Soak & 1753 & 5 & - \\
\hline 6 & Ramp & 1793 & 10 & 2 \\
\hline 7 & Soak & 1793 & 20 & - \\
\hline 8 & Ramp & 1673 & 5 & 20 \\
\hline 9 & END & - & - & \\
\hline
\end{tabular}

\section{Results}

\subsection{Results of mechanical testing}

The results of mechanical testing are given in fig. 2. It is visible from fig. 2 that tensile strength $R_{m}$ decrease slightly with increase of sintering cycle. On the other hand the value of yield strength $\boldsymbol{R}_{\mathbf{p} 0,2}$ remains rather constant. The elongation depends strongly on number of sintering cycles (sintering time) and decrease simultaneously from $21 \%$ for one to approximately $7 \%$ after 15 sintering cycles.

The decrease of elongation of tungsten heavy alloy with increase of sintering time shows that the material is going to be brittle and shows that there is no strain hardening while the specimen is tensile tested.

\subsection{Microstructure observations}

In fig 3 the examples of THA microstructure are shown. The micrographs are purposely given at the same magnification to allow immediate comparison of tungsten grains diameter. 
a.

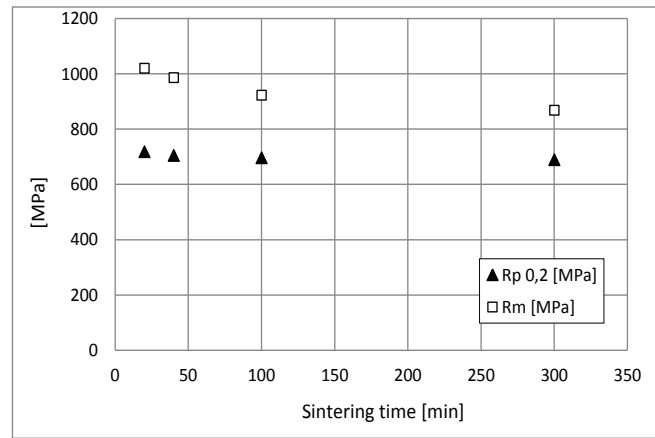

b.

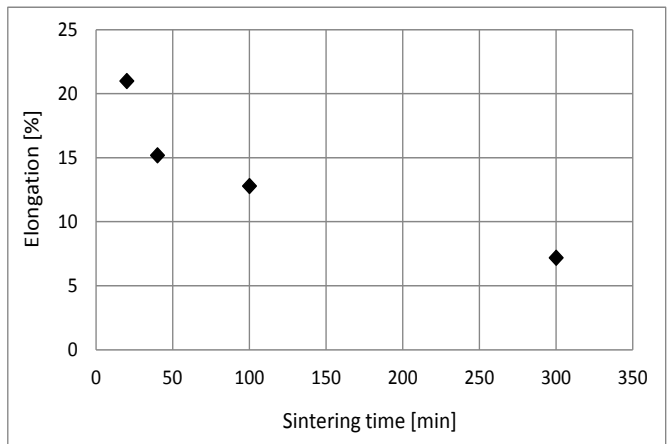

Fig. 2.The results of tensile test as function of sintering cycles: $\mathrm{a}$ - tensile and yield strength and $\mathrm{b}$ - elongation

The immediate comparison of micrographs show increase of size of tungsten grains. This was proved with qualitative measurements including at least from 35 to 50 measurements in two perpendicular directions. The average values of measured: areas and equivalent diameters of tungsten grains are given in table 2. The equivalent diameter is the radius of circle whose area is equal to the surface area of real grain which is not ideal circular (see fig. 3).

Table 2.

The summarized results of tungsten size measurements

\begin{tabular}{cccccc}
\hline \multirow{2}{*}{\begin{tabular}{c} 
Number of $\begin{array}{c}\text { sintering } \\
\text { cycles }\end{array}$ \\
\multirow{2}{*}{1 cycle }
\end{tabular}} & $\begin{array}{c}\text { Direction of } \\
\text { cross-section }\end{array}$ & $\begin{array}{c}\text { Grain } \\
\text { area }\end{array}$ & $\begin{array}{c}\text { Diameter } \\
\text { equivalent }\end{array}$ & $\begin{array}{c}\text { Grain } \\
\text { high }\end{array}$ & $\begin{array}{c}\text { Grain } \\
\text { width }\end{array}$ \\
\cline { 2 - 6 } & transverse & 1021,48 & 31,47 & 33,12 & 33,39 \\
\hline \multirow{2}{*}{2 cycles } & longitudinal & 413,22 & 22,67 & 22,33 & 22,33 \\
\cline { 2 - 6 } & transverse & 1204,63 & 35,40 & 36,30 & 38,77 \\
\cline { 2 - 6 } & longitudinal & 437,82 & 21,95 & 22,96 & 23,71 \\
\hline \multirow{2}{*}{5 cycles } & transverse & 2343,86 & 52,32 & 55,23 & 55,17 \\
\cline { 2 - 6 } & longitudinal & 1636,84 & 39,67 & 40,99 & 43,57 \\
\hline \multirow{2}{*}{15 cycles } & transverse & 4864,74 & 72,02 & 76,57 & 78,90 \\
\cline { 2 - 6 } & longitudinal & 4311,81 & 67,33 & 73,69 & 71,86 \\
\hline
\end{tabular}

a.

b.

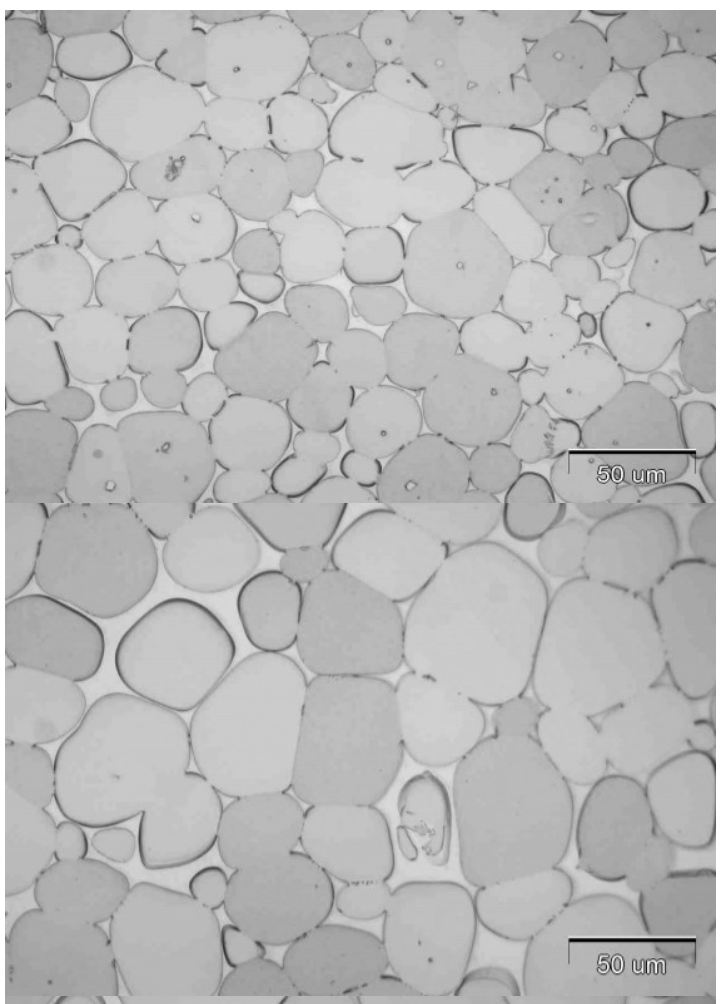

c.

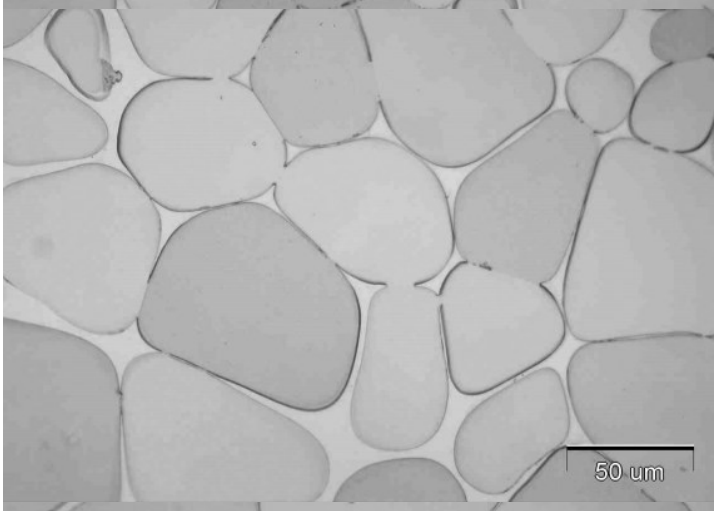

d.

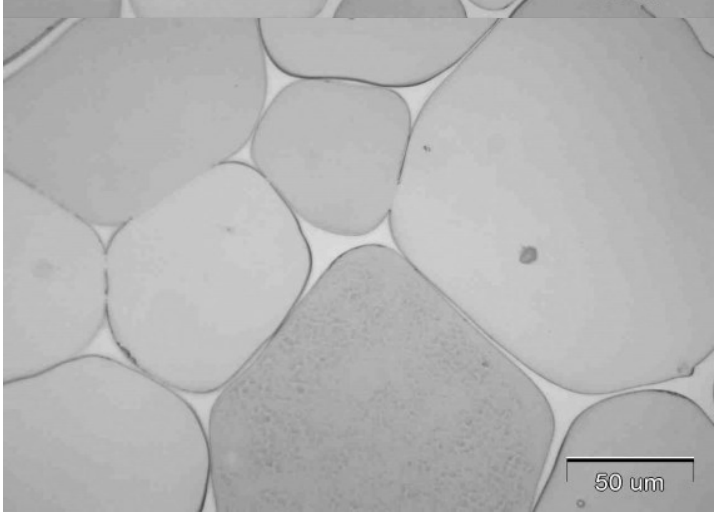

Fig. 3. The microstructure of THA after different number of sintering cycles: a - 1 cycle, $\mathrm{b}-2$ cycle, $\mathrm{c}-5$ cycles and $\mathrm{d}-15$ cycles 
There are several pieces of interesting information in the table. As was said before, the surface area of tungsten grain increases with the number of sintering cycles. Similarly, diameter of equivalent grain size increases with number of sintering cycles. Moreover, it follows from the two last columns of table 1 that the tungsten grains are going to be more symmetric with increase of sintering cycles. This is indicated by decreasing of difference between grain height and width measured in direction longitudinal and across with respect to the specimen axis.

\subsection{SEM investigations}

Fig. 4 and 5 show examples of fracture surface morphology observed in SEM. First set of micrographs (fig. 4) represents the results obtained for the specimen subjected: one (fig. 4 a), five (fig. 3b) and fifteen sintering cycles (fig. 3c). The main difference between the morphology of fracture surface is the size of tungsten grains. In the first photo (fig. 4a) it is very difficult to see cleavage planes which are clearly visible in two next micrographs (fig. $4 \mathrm{~b}$ and c) taken from specimen sintered 5 and 15 times. In this case the cleavage planes which, according to literature $[5,6]$ are $\{100\}$ or $\{101\}$ type planes, are very rarely visible in specimen subjected to one sintering cycle.

a.

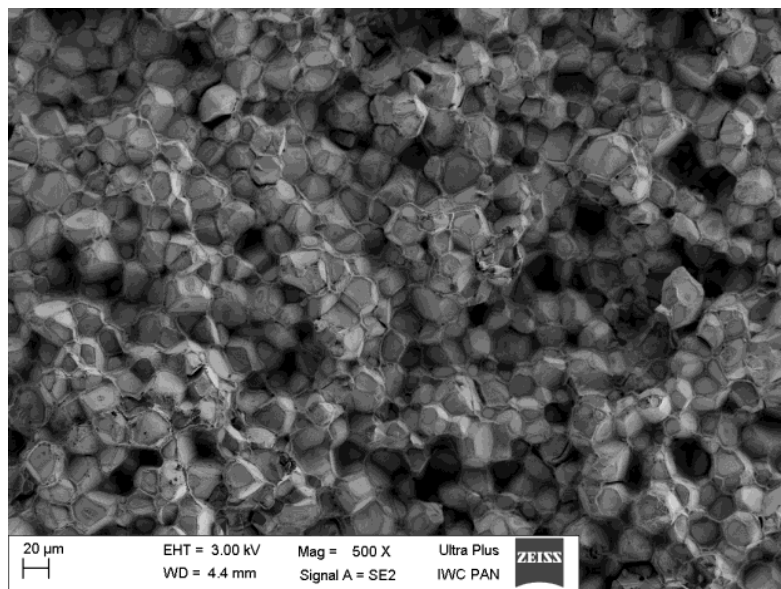

b.

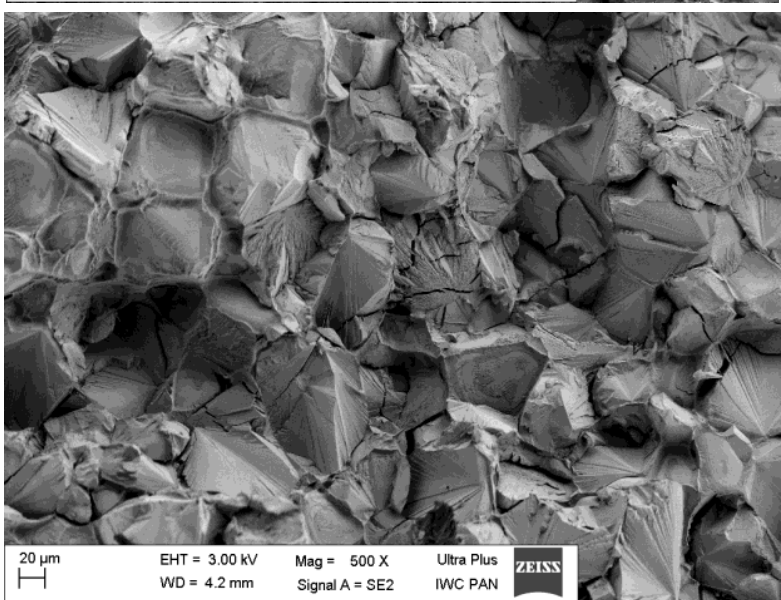

c.

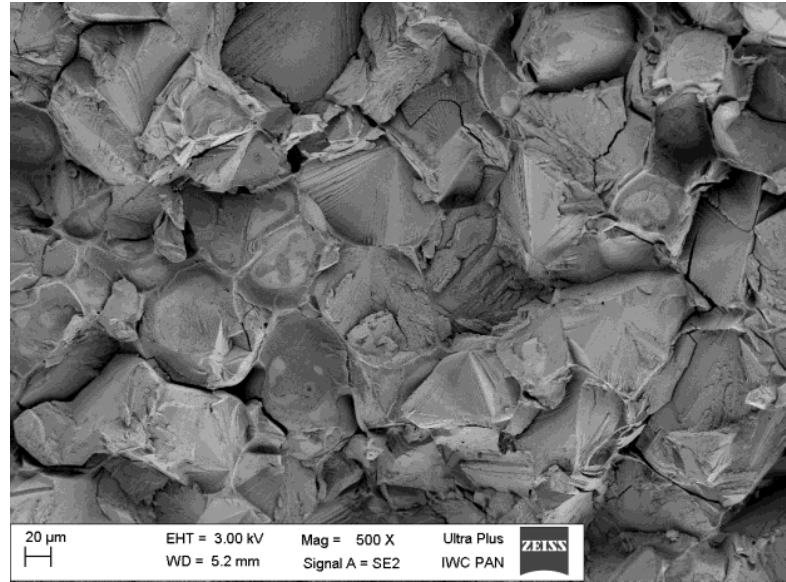

Fig. 4. The morphology of fracture surface of specimens subjected to: $\mathrm{a}-1, \mathrm{~b}-5$ and $\mathrm{c}-15$ sintering cycles

a.

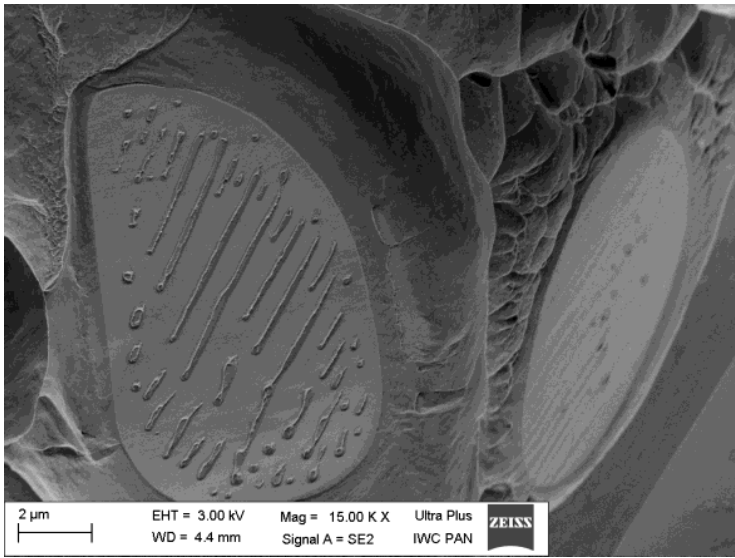

b.

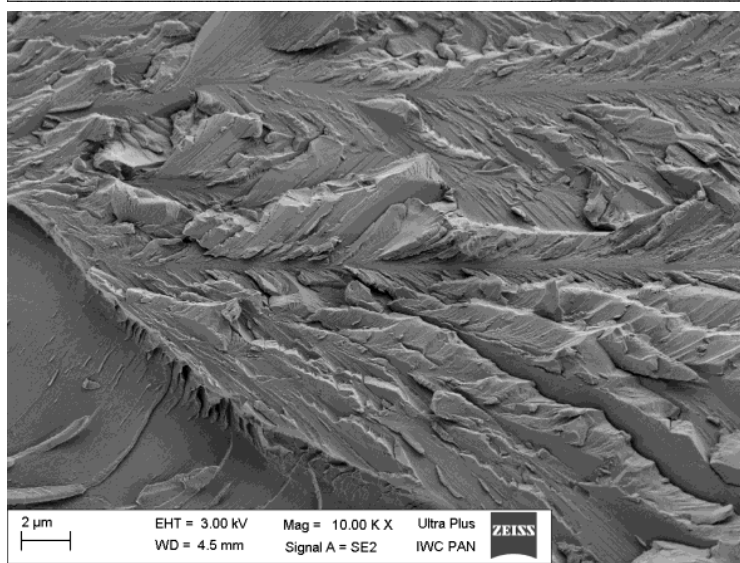

Fig. 5. The morphology of fracture surface structure of specimen after: $\mathrm{a}-$ one and $\mathrm{b}-15$ sintering cycles

Fig. 5 presents the results of SEM studies carried out at much higher magnification. These reveal some details of fracture surfaces not observable at small magnification. The first micrograph (fig. 5a) shows some specific feature of fracture plane. These are the marks looking like long precipitates or dents 
on the flat tungsten grain plane embedded with dimples surrounding with Ni-base matrix. The dimples are characteristic for ductile mode of fracture [7]. Contradictory to shallow dimples visible in the right upper corner of the micrograph (fig. 5a) the flat plane being the place of immediate contact between tungsten grains is typical for brittle mode of intergranular fracture. The scanning electron micrograph visible in fig. $5 \mathrm{~b}$ reveals so called chevron marks, characteristic for brittle cleavage type fracture mode [7]. It should be noted here that in specimens with brittle mode fracture surfaces (after 5 and 15 cycles) secondary cracks were often observed.

\section{Discussion of results}

First of all the authors would like to concentrate on results of mechanical testing. As it was stated before, the cyclic sintering has minor influence on yield stress (fig. 2a) while the tensile strength decreases with increase of number of sintering cycles. This decrease is accompanied with simultaneous decrease of plasticity which is proved by decreasing elongation. Plasticity decrease is also evidenced by the morphology of fracture surface which is changed from mixed to brittle mode. It is interesting to note here that the microstructure observations discovered drastic increase of tungsten grain with increase of number of sintering cycles.

In fig. 7 the authors showed the dependence of tensile strength on average size of tungsten grains. It looks from the graph that the size of tungsten grains depends linearly on number of sintering cycles. If neglect the time needed for reaching temperature of sintering equal $1793 \mathrm{~K}\left(1520^{\circ} \mathrm{C}\right)$ then the total sintering time would be the product of cycles number $\mathrm{N}$ and time of each sintering cycle equal 20 minutes. Thanks to this "operation" the total sintering time for $\mathrm{N}=1,2,5$ and 15 cycles would be 20,40 , 100 and 300 minutes respectively. Although this is rough simplification the dependence of equivalent tungsten grain size on total sintering time (TST) is exactly the same as in case where horizontal axis is number o cycles - $\mathrm{N}$.

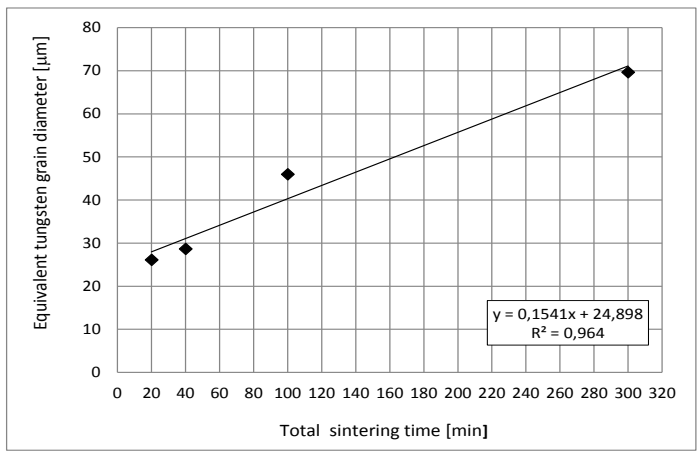

Fig. 6. The dependence of equivalent tungsten grain diameter on number of sintering cycles

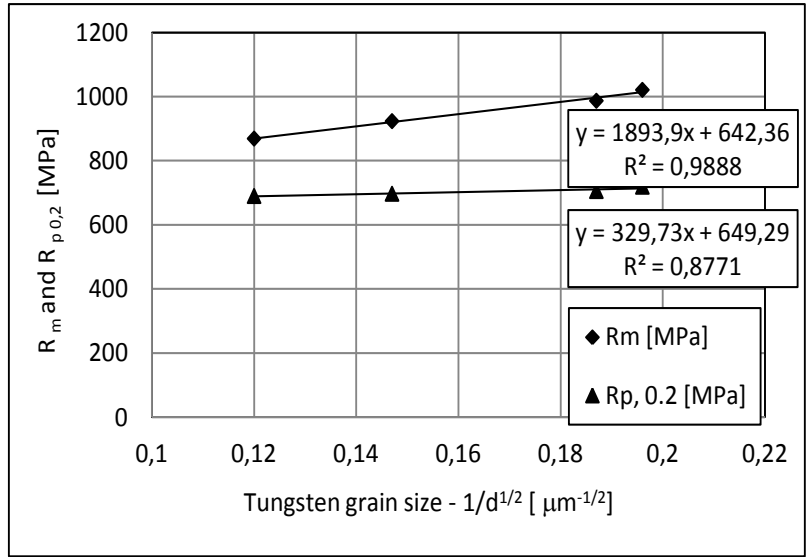

Fig. 7. The relationship between tensile and yield strength and the value of $1 / d^{1 / 2}$

Even more interesting is the dependence of tensile and yield strength on the value $1 / \mathrm{d}^{-1 / 2}$ which is showed in fig. 7 . This relationship is rather surprising because there is a well known Halla-Petcha relationship describing dependence of yield and not tensile strength on grain size expressed as function of $1 / \mathrm{d}^{1 / 2}$. On the other hand the high value of $\mathrm{R}^{2}$ looks very convincing. Finally we would like to discuss specific marks identified on the fracture surface (fig. 4a). These marks were observed before in tungsten heavy alloys but still now there is more suspicion than final interpretation based on experimental data. It is worth to recall two photos from our earlier studies concerning matrix structure observations carried out with transmission electron microscope (TEM). Fig. 8 shows the electron micrograph of the Ni-based THA matrix with characteristic rod-like precipitates being intemetallic phase $(\mathrm{Ni}, \mathrm{Fe}, \mathrm{Co})_{4} \mathrm{~W}[6,7]$. The evidence of this phase was documented in our investigations presented in [8].

If compare the size and morphology of precipitates showed in fig. 8 with the marks observed in fig. $5 \mathrm{a}$ it is clear that the last one can be either dents of hard intermetallic phase on tungsten grain surface or precipitates formed at tungsten grain - matrix interface. The different shape of marks on tungsten grain surface (fig. 5a) (elongated or compact) reflects the different crystallographic orientation of precipitates with respect to the interface. This is evidenced in TEM photo (fig. 8) where the rod-like phase shows also different morphology. It is very likely that the process of nucleation and growth of intermetallic phase started at W-matrix interface during first steps of solidification liquid matrix and is continued during cooling. The precipitation reaction proceeding between tungsten and $\mathrm{Ni}$ is very probable because of limited solid solution $\mathrm{W}$ in Ni decreasing with temperature decrease. 
a.

b.

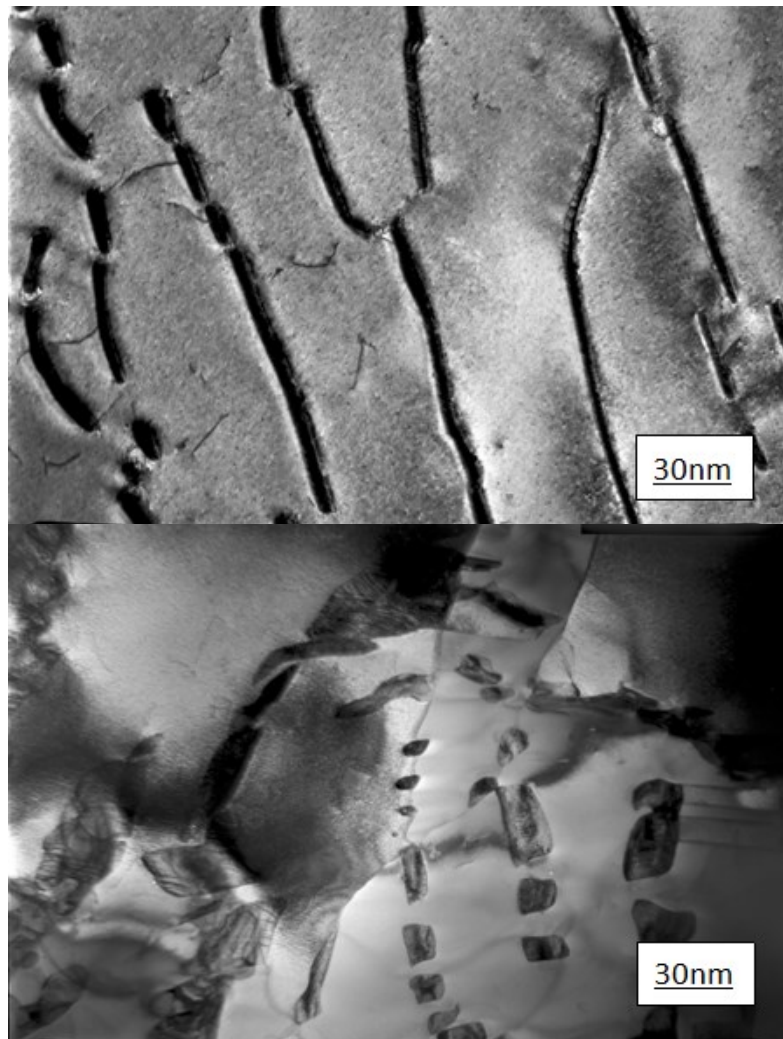

Fig. 8. Transmission electron micrograph of tungsten heavy alloy showing eutectic mixture of rod-like $\mathrm{Ni}_{4} \mathrm{~W}$ precipitates with Ni-based matrix (magnification 30.000) [7]

\section{Conclusions}

The tungsten heavy alloys are very attractive material for many applications. Because of very high melting point it is usually shaped using powder metallurgy. This manufacturing process is much more complicated than conventional shaping like casting or metal forming. The details and problems concerning liquid phase sintering of tungsten heavy alloys are described by Randal and coworkers [9]. These problems leading often to fault structure and mechanical properties need to be corrected with heat treatment. Very often the simplest way to assure correct properties is the second sintering cycle. As was shown in the investigation presented here the each next sintering cycle influences the structure and properties of THA. On the basis of the results gathered in our investigations the following statements are proposed:

1. The increase of number of liquid phase sintering cycles leads to increase of tungsten grain size. The value of equivalent tungsten grain size is linearly dependent on total liquid sintering time.

2. Increasing of LPS cycles decreases the tensile strength which is accompanied with drastic elongation decrease.

3. The elongation decrease is accompanied with brittleness increase which is documented with fracture mode changes.
4. The increase of THA brittleness is mainly responsible for decrease of tensile strength, whereas it does not influence the proof stress.

5. The increase of brittleness with increase of number of LPS cycles results probably from so called hydrogen embrittlement. This has been caused by long time subjecting of molten Ni-base matrix to the influence of hydrogen atmosphere. The standard 3 hour aging at temperature $1100^{\circ} \mathrm{C}$ in vacuum furnace being enough in case of one cycle sintering was not sufficient to remove whole amount of hydrogen introduced into THA during multi-cycle liquid phase sintering.

6. The tensile strength fits the Hall-Petch relationship and increases linearly with increase $1 / \mathrm{d}^{1 / 2}$.

\section{Acknowledgments}

This work was supported under grant No: 504/02071/1101

\section{References}

[1] Germam, R.M. (1992). Proc. International Conference on Tungsten and Tungsten Alloys, eds. A. Bose and R.J. Dowling, MPIF, Princeton, New Jersey, pp. 3-12.

[2] Magness, L.S. (1995). Proc. International Conference on Tungsten and Tungsten Alloys, ds. A. Bose and R.J. Dowling, MPIF, Princeton, New Jersey, pp. 133-142.

[3] Kaczorowski, M., Skoczylas, P. \& Krzyńska, A. (2011). The influence of $\mathrm{Fe}$ content on spreading ability of tungsten heavy alloys matrix on tungsten surface. Archives of Foundry Engineering. 11(3), 103-106.

[4] Kaczorowski, M., Skoczylas, P. (2015). Formation of structure and properties of tungsten heavy alloys of special purpose. Problemy Mechatroniki. pp. 27-40. Uzbrojenie, lotnictwo, Inżynieria Bezpieczeństwa.

[5] Cordwell, J.E., Hull D. (1971). Observation of $\{110\}$ cleavage in $<110>$ axis tungsten single crystals, 26(1), pp. 215-224.

[6] Riedle, J., Gumbsch, P., Fischmeister, H.F., Glebovsky, V.G. \& Semenov, V.N. (1994). Fracture studies of tungsten single crystals. Materials Letter. 20(5-6), 311-317.

[7] (1978). Metals Handbook vol.12 Fractography, Ninth Edition, Metals Park, Ohio.

[8] Kaczorowski, M., Skoczylas, P. \& Nowak, W. (2008). The study of precipitation hardening of weight heavy alloys matrix. Archives of Foundry Engineering. 34(1), 169-174.

[9] Kaczorowski, M., Skoczylas, P., Krzyńska, A. \& Kaniewski, J. (2012). The strengthening of weight heavy alloys during heat treatment, Archives of Foundry Engineering. 12(4), 7580 .

[10] German, R.M., Suri, P., Park, S.J. (2009). Review: Liquid Phase Sintering. Journal of Materials Science. 44, 1-39. 